\title{
A review on ethical concerns in big data management
}

\section{Suja R. Nair}

\author{
Educe Micro Research, \\ Rajarajeswari Nagar, Bengaluru - 560098, India \\ Email: sujarnair@rediffmail.com
}

\begin{abstract}
In the contemporary digitalised age, big data analytics have enabled organisations to automate and analyse multiple sources of data and information quickly such that it facilitates optimised decision making process that help in achieving organisational goals. While, from a strategic perspective analysing of the data for eventual analysis is vital, given the availability of varieties of data that can be accessed from multiple media sources makes big data management highly challenging. Moreover, given that big data analyses data very fast, it enables access to data-information which could compromise (either inadvertently or deliberately) individual privacy, be misused, etc. raising ethical issues concerning the sharing and usage of data. To address these concerns on ethicality in big data management, this study proposes to use a simple 'stakeholders-ethics-framework' to develop a 'stakeholder analysis approach framework' suggestive be linked to sustainability guidelines that help towards a sustainable big data industry, is assumed.
\end{abstract}

Keywords: big data analytics; large data management; ethical in big data; stakeholder analysis approach; stakeholder ethics framework; sustainability.

Reference to this paper should be made as follows: Nair, S.R. (2020) 'A review on ethical concerns in big data management', Int. J. Big Data Management, Vol. 1, No. 1, pp.8-25.

Biographical notes: Suja R. Nair holds a PhD, MBA and BA (Hons.) degrees and has 25 years of work experience, which includes corporate, academics and research. She is an independent researcher and author since 1999, and also handles Strategic Marketing at Educe Micro Research, Bangalore, India, since 2002. As a prolific writer she has written many text-books in the areas of marketing research, consumer behaviour, retail management and organisational behaviour, which are widely read and recommended by leading universities/institutes in India. Her papers/chapters have been published in referred international and Indian journal publications. She is an editor of Handbook of Research on Ethics, Entrepreneurship and Governance in Higher Education, an associate editor of International Journal of Big Data Management and an editorial board member of IAFOR Journal of Education. Her major fields of research interest include ethics, higher education management, women-entrepreneurship, cause-related marketing, retail-marketing and consumer behaviour. 


\section{Introduction}

In the contemporary market scenario, the term 'big data' has been gaining a lot of attention from organisations and decision makers who use it to obtain fruitful insights on building capabilities and to gain competitive advantage (Blackburn et al., 2017; Lee, 2017; Oussous et al., 2018). Big data facilitates gathering of real-time data from millions of end users via popular social networking services like LinkedIn, Facebook, Twitter, Netflix etc. with big data analytics used in real-time to direct, automate and optimise the decision making processes that help towards achieving the organisational goals. Big data management would require analysing the collected data such that it helps to understand users' data consumption behaviour, add value to other applications like monitoring network traffic, creating business models, and so on, that enable organisations realise the social and economic value from the big data (Günther et el., 2017; Mazzei and Noble, 2017; Oussous et al., 2018; Verma, 2017).

Big data development is rapidly evolving, driven by the social media and information technology phenomenon that require organisations to build capabilities and leverage big data in order to be competitive (Lee, 2017; Sharma et al., 2014). Big data improves functional capabilities and can influence organisational strategic management to redefine innovations, competition and productivity (Mazzei and Noble, 2017). It also helps in the creation of new knowledge and knowledge management in various fields of application (Del Vecchio et al., 2018; Fredriksson, 2018; Pauleen and Wang, 2017). For instance, data analytics involving usage of internet of things (IoT) has helped to create and build intelligent healthcare monitoring systems (Srinivasa et al., 2018). Indeed, big data has the potential to support and improve decision-making in organisations, noted Elgendy and Elragal (2016), and alongside the ability to increase efficiency in public sector organisations, observed Fredriksson (2018).

While above studies stated how usage of big data can reap benefits that help organisations to leverage information from diverse sources to create knowledge, better the decision making process, create business models, influence organisational strategic making and gain competitive advantage, there are researchers who have raised questions on the ethicality in its applications (Chessell, 2014; Martin, 2015; etc.), especially given that business ethics have got measurable economic benefits (Lipska and Kijanka, 2019; Nair and Saiz-Alvarez, 2019). When organisations use big data analytics to enhance their operations they may not know whether using of the technology is ethical, noted Chessell (2014), while, Martin (2015) identified ethical issues that may arise from reselling consumers' data to the secondary market. Another study (Hyrynsalmi et al., 2017) referred to ethical issues on utilising data-driven gamifcation, i.e., collecting data from the user and using it to modify the behaviour of users, wherein the data-driven gamifed solutions although done with good intentions, could end up causing more harm than good, albeit, unintentionally. Similarly, Herschel and Miori (2017) argued that while big data facilitate organisations to rapidly capture, analyse, and exploit information, it also enables access to data which could compromise individual privacy either deliberately or inadvertently, which is again an ethical concern. Mittelstadt and Floridi (2016) found the ethical issues foreseen in the biomedical context concern ignoring the group-level ethical harms, change in the nature of fiduciary relationships, lack of clarity in distinguishing between 'academic' and 'commercial' big data practices that could potentially harm the data subjects involved, insufficient necessary resources and intellectual property rights 
based on the analysis of aggregated datasets. Meanwhile, Devlin (2017) felt a difficult challenge for the data industry is to apply ethical judgment on the whole data analytics process of the project undertaken; right from requirement onwards till the eventual decommissioning.

Nonetheless, given the intense competition at the market place, availability of huge, varied and complex datasets with the organisations is likely to be used for working out organisational strategies. Meanwhile, the debate will also continue on how organisations can realise value from big data at different levels of analysis (Günther et al., 2017), especially since the stream of digitalised data will require integration of individuals, processes and organisations to deal with the same in an ethical manner (Knoppers and Thorogood, 2017).

On the one hand prior literature have indicated the utility of big data analytics and also raised concerns on the issue of ethics in its usage and application. While on the other hand, big data as a multidisciplinary and evolutionary fusion of new technologies will contribute towards developing strategic insights and sustainable developments; argue recent studies (Ahmad et al., 2019; Bumblauskas et al., 2017). This gives rise to a research and managerial problem to obtain insights on the management of big data, in order to develop clear-sightedness on its sustainable development through examining its ethical applications. To probe this, the following research question is framed:

RQ How to address the ethical concerns on data analytics usage from a sustainable perspective?

This study could be categorised as a 'general review' paper that aims to review existing literature in the field of ethics in big data usage and management, in an attempt to answer the research question. To obtain insights on how to deal with ethical concerns on data analytics usages from a sustainable perspective, the normative stakeholder theory concept (Friedman and Miles, 2006) proposing stakeholders should act and view the purpose of organisation on the basis of ethical principles is felt would be helpful. In line to this, the core components of 'methodology alignment framework' regarding ethical decisions in the context of big data (Davis and Patterson, 2012) was considered and adapted. The reason for adaptation of this framework is because Davis and Patterson (2012) contend their suggested approach can be used to engage in explicit ethical inquiry on big data usage in all types of situations. Moreover, previous researchers felt it necessary to have proactive stakeholder relationships that help develop strategies to enhance sustainable innovations and growth (Vershinina et al., 2019), to develop insights on how to design, deliver and evaluate stakeholder value on the basis of the verified data (Shams and Solima, 2019). Hence, going by the above discussions we propose to develop a 'stakeholder analysis approach framework' that suggests linking the ethical issues in big data to stakeholders' analysis, and consists of: mapping stakeholders' interests, regulatory/governing bodies, a stakeholders ethics framework and certain sustainability guidelines.

This study would interest managers who can use the suggested framework to focus on effective organisational resources management in big data initiatives, take strategic decisions to utilise the results of explicit ethical inquiry on big data usage through stakeholders' involvement to earn competitive advantage. For academics, this study will help in the application of ethicality in big data technology to the e-learning process.

The rest of the paper is organised as follows: Section 2 pertaining to background literature will discuss big data and data analytics, followed by Section 3 on ethical 
concerns in big data management. In Section 4 discussions will be related addressing ethics in big data through the involvement of stakeholders, and in Section 5, summary and conclusions, including limitations, implications and future research areas are discussed.

\section{Background literature}

\subsection{Big data and data analytics}

In the contemporary digitalised world the need to access information content has resulted in the popularity of the term 'big data' among the corporate, information technology practitioners and researchers. Even though big data is used in various contexts: confluence of a whole set of trends in computing, information processing, computational methods, analytical tools, information on the socio-cultural shift affecting the business and society, etc. there is no common formal definition of big data, noted Blackburn et al. (2017) and De Mauro et al. (2015), which implies that 'big data' would have different meanings, interpretations and implications for different organisations, concluded Blackburn et al. (2017).

While, prior studies (Elgendy and Elragal, 2016; Mukred and Jiianguo, 2017) indicated that 'big data' is characterised by the $4 \mathrm{~V}$ 's, namely, volume, velocity, variety and veracity, other researchers added another $\mathrm{V}$, 'value' provided to users who use the analysed data information to make the right decisions (Anshari and Alas, 2015; Elgendy and Elragal, 2016; Emani et al., 2015; Gandomi and Haider, 2015). Meanwhile, given that most of the papers on 'big data' dealt with one or more of the following themes, De Mauro et al. (2015) identified four fundamental 'themes' or 'prevalent concepts' that represent the essential components of big data, namely, information, technology, methods and impact. Furthermore, taking into consideration the existing definitions of big data and the associated main research topics, De Mauro et al. (2015, p.103) proposed a formal definition, "Big data represents the information assets characterised by such a high volume, velocity and variety to require specific technology and analytical methods for its transformation into value." This definition of big data directly refers to the use of specific technology and methods to analyse the information.

However, Gandomi and Haider (2015) argue that given the characteristics of big data: high magnitude/volume of data, structural heterogeneity/variety of structured and unstructured data, velocity/rate and speed at which huge data are generated, veracity, i.e., dealing with imprecise and uncertain data, variability/variations in the data flow rates and complexity, and value, i.e., low value density, organisations will need to use data analytic techniques to analyse and acquire intelligence from the big data. Moreover, technology as the 'backbone' of business intelligence systems enable organisations access to high quality, targeted information through big data analytics usage that help in understanding market positions, optimise strategic decision making, and monitoring organisational competitiveness, add Harrison et al. (2015).

Given the intense competition at the market place and availability of huge, varied and complex datasets, the debate continues on how organisations can realise value from big data, at different levels of analysis, noted Günther et al. (2017). Elgendy and Elragal (2016) observed that digital technologies generate enormous amount of data that need to be stored and analysed to extract the value that facilitates integration of data analytics 
into the decision making process of the organisation. For example, using big data, retail organisations could acquire intelligence inputs on the store traffic, the age or gender composition of their customers, and their in-store movement patterns, which can be leveraged in taking decisions on product-promotion policies, selection and placement of the staff, and so on. Thus, situational requirement would mandate organisations to use technological capabilities in taking timely, accurate, and effective operational and strategic decisions using big data management techniques. Moreover, continuous technological advancements and developments is going to provide more stream of digitalised data requiring the integration of individuals, processes and organisations in using this information for knowledge management, innovations, competitive advantage, add business value, etc. (Akter and Wamba, 2016; Elgendy and Elragal, 2016; Mazzei and Noble, 2017; Sivarajah et al., 2017). Interestingly, Günther et al. (2017) felt organisations can realise value from big data at the individual level through data portability and interconnectivity, and interactions at various levels through alignment of work practices, organisation-business models and stakeholders' interests.

Going by the above discussion it may be said big data has the potential to provide organisations with valued insights on enhancing their decision-making process, while big data analytics refer to the various analytic tools and techniques deployed by organisations to improve their operational efficiency, with the strategic potential being to drive new revenue streams and gain competitive advantage.

\section{Ethical concerns in big data management}

While digital data enable organisations access to huge volumes of information that can have strategic implications, its rapid evolution and adoption at large has prompted researchers to raise questions on the ethicality involved in the sharing and usage of big data (Abouelmehdi et al., 2017; Davis and Patterson, 2012; Institute of Big Ethics, 2016; Martin, 2015; Zwitter, 2014). Amassing lots of information through big data can affect the behaviour of people using it; raising ethical concerns on violation of the fundamental civil, social, political, and legal rights observed Davis and Patterson (2012). The speed of big data development impacting individual ability to understand its potential in taking informed decisions is suggestive of the need to rethink on the philosophy of professional ethics, policy-making, and research, stated Zwitter (2014). Referring to the increasing privacy and risk concerns in view of identity theft, questionable marketing practices, data mining and profiling, LaBrie et al. (2014) felt it is very important to explore consumers' feelings and reactions to the usage of their data.

Institute of Big Ethics (2016) feels that in this era of big data, responsible businesses should address ethical issues such as: respect of privacy and security when using personal information, take consent prior to processing personal information, and provide for fair treatment of stakeholders and integrity in big data usage. Taking the example of healthcare research, Abouelmehdi et al. (2017) although concurring on plethora opportunities available for using big data to drive up research in this field, pointed to number of obstacles and challenges termed as technical, skilled talent, privacy and security issues, which could impede the true potential of health-related research. Furthermore, organisations should shoulder the responsibility to promote transparency and prevent the misuse of information on personal data otherwise, the consequences and 
repercussions of misuse or questionable ethical usage of big data can have a significant effect on the company reputation, undermining the existing internal and external trust, affecting customer relationships and even the revenues, adds the Institute of Big Ethics (2016).

While organisations apply big data to enhance their operations, Chessell (2014) argues given that the core of the organisation-its customers and stakeholders are all 'just people' who may have different perspectives on the ethicality concerning the usage of data analytics, organisations should take into consideration the wider implications on usage of big data technology. Moreover, awareness among today's consumers on the amount of information being collected and the different ways in which it is being used could result in massive consumer backlash, in the event of its perceived abused usage, opined LaBrie et al. (2014). Hence, organisations need to exercise care when selecting information practices, ensuring these are helpful to the business, and that its constituents are ethically sound, added these researchers. Additionally, Martin (2015) referring to 'big data' as an industry identified ethical issues at two levels:

1 at the industry level, these are externalities like surveillance or broad (hidden) tracking of consumers and collection, aggregation and use of the data/ information-such as breaching privacy expectations

2 at the supply chain level, destructive demand, wherein the need for consumer data pressurise firms to collect and sell large amounts of information with lower standards-from unknown or questionable sources.

In line to prior studies, a recent study (Lokshina and Lanting, 2018) raised ethicality concerns on big data usage, i.e., whether due respect is given to the original intended use of the data, questioning issues like-anonymity, privacy, sharing of datasets, drawing not-justifiable and inappropriate conclusions, creation of fake news, and so on.

Incidentally, while referring to the capacity of big data to collect and analyse gigantic datasets of information, Mittelstadt and Floridi (2016) identified the key areas (or themes) of ethical concerns as:

1 informed consent

2 privacy issue (inclusive of anonymisation and data protection)

3 ownership

4 epistemology and objectivity

5 'big data divides' that is created between those who have and those who lack the necessary resources to analyse the increasingly large datasets.

These researchers further suggest that the themes may be used to develop a critical framework which provides the guidance in making an ethical assessment and governance on the emerging big data practices. Whereas, Floridi and Taddeo $(2016$, p.3) asserted that "the ethical challenges posed by data science can be mapped within the conceptual space delineated by the three axes of research: the ethics of data, the ethics of algorithms and the ethics of practices", which though distinct lines of research; are also intertwined.

Table 1 provides a brief outline on selective studies addressing ethical concerns in big data. 
Table 1 Brief outline on selective studies of big data ethics

\begin{tabular}{lll}
\hline Research publication & \multicolumn{1}{c}{ Purpose of study } & Findings/conclusions of study \\
\hline Davis, K. and Patterson, D. & To discuss the implications & $\begin{array}{l}\text { Suggested a 'framework' to } \\
\text { (2012) Ethics of Big Data, }\end{array}$ \\
of ethics of big data & $\begin{array}{l}\text { valore the relationship between } \\
\text { O'Reilly Media, Inc., }\end{array}$ & as members of a common \\
Sebastopol, USA. & enterprise - and aligning these to \\
& & the actions taken to build and \\
& manage products and services \\
& using big data technologies.
\end{tabular}

Zwitter, A. (2014) 'Big data ethics', Big Data \& Society, July-December, pp.1-6.

Martin, K.E. (2015) 'Ethical issues in the big data industry', MIS Quarterly Executive, Vol. 14, No. 2, pp.67-85.

Chessell, M. (2014) Ethics for Big Data and Analytics, IBM.

Mittelstadt, BD. and Floridi, L. (2016) 'The ethics of big data: current and foreseeable issues in biomedical contexts', Science and Engineering Ethics, Vol. 22, No. 2, pp.303-341.

Floridi, L. and Taddeo, M. (2016) 'What is data ethics?', Philosophical Transactions of The Royal Society: A Mathematical, Physical and Engineering Sciences, Vol. 374, No. 2083 [online] https://doi/full/10.1098/ rsta.2016.0360

Abouelmehdi, K., Beni-Hssane, Khaloufi, H. and Sadi, M. (2017) 'Big-data security and privacy in healthcare: a review', Procedia Computer Science, Vol. 113, pp.73-80.
To elaborate on the ways big data has impact on ethical conceptions.

To analyse big data as an industry, and identify the ethical issues faced by it.

To determine why questions are raised about the ethics of analytics and big data given that they reap huge benefits to individuals and organisations?

Systematically analyse and understand the ethical implications of biomedical big data.

To highlight the need for ethical analyses to focus on the content and nature of computational operations more than on the variety of digital technologies.

\section{To discuss the} state-of-the-art security and privacy issues in big data when applied to the healthcare industry.
Big data have strong effects on assumptions about the individual responsibility to live in a datafied world, need to prevent the abuse of big data as a source of information and power.

Ethical issues arise from reselling consumers' data to the secondary market for big data, for which remedies were proposed, with the goal to foster a sustainable big data industry; suggests guidelines for a sustainable big data industry.

Suggested organisations to thoughtfully consider the 'ethical awareness framework' when using analytics and big data.

Using a thematic narrative, metaanalysis of the literature helped to identify key areas concerning the ethical risks in the usage of biomedical big data.

The ethical challenges put forth by data sciences can be mapped within the conceptual space delineated by the three axes of research, namely, the ethics of data, the ethics of algorithms and the ethics of practices.

The available data privacy, data security, users' accessing mechanisms and strategies applicable to the industry were discussed. 
Table 1 Brief outline on selective studies of big data ethics (continued)

\begin{tabular}{|c|c|c|}
\hline Research publication & Purpose of study & Findings/conclusions of study \\
\hline $\begin{array}{l}\text { Günther, W.A., } \\
\text { Mehrizi, M.H.R., Huysman, M. } \\
\text { and Feldberg, F. (2017) } \\
\text { 'Debating big data: a literature } \\
\text { review on realizing value from } \\
\text { big data', The Journal of } \\
\text { Strategic Information Systems, } \\
\text { Vol. 26, No. 3, pp.191-209. }\end{array}$ & $\begin{array}{l}\text { To conduct an in-depth } \\
\text { systematic review of } \\
\text { literature on the topic of } \\
\text { big data and debate on } \\
\text { how organisations can } \\
\text { realise value from big data, } \\
\text { at different levels of } \\
\text { analysis. }\end{array}$ & $\begin{array}{l}\text { The study identified two } \\
\text { socio-technical features of big } \\
\text { data, namely, portability and } \\
\text { interconnectivity that influences } \\
\text { value realisation. }\end{array}$ \\
\hline $\begin{array}{l}\text { LaBrie, R.C., Cazier, J.A. and } \\
\text { Steinke, G.H. (2014) 'Big data } \\
\text { ethics: a longitudinal study of } \\
\text { consumer, business and societal } \\
\text { perceptions', Journal of } \\
\text { Management Systems, Vol. 24, } \\
\text { No. 2, pp.23-38. }\end{array}$ & $\begin{array}{l}\text { To investigate changing } \\
\text { attitudes towards the } \\
\text { collection and use of } \\
\text { personal data, big data, } \\
\text { data mining and data } \\
\text { warehousing by business } \\
\text { and governments using } \\
\text { longitudinal data. }\end{array}$ & $\begin{array}{l}\text { Consumers were more } \\
\text { comfortable sharing their data, } \\
\text { have slightly more favourable } \\
\text { perceptions of business value } \\
\text { when implementing big data } \\
\text { technology during the period } \\
2013-2014 \text { than a decade ago } \\
\text { during 2003-2004. }\end{array}$ \\
\hline $\begin{array}{l}\text { Lokshina, I.V. and } \\
\text { Lanting, C.J.M. (2018) } \\
\text { 'Addressing ethical concerns of } \\
\text { big data as a prerequisite for a } \\
\text { sustainable big data industry', } \\
\text { International Journal of } \\
\text { Interdisciplinary } \\
\text { Telecommunications and } \\
\text { Networking, Vol. 10, No. 3, } \\
\text { pp.33-54. }\end{array}$ & $\begin{array}{l}\text { To analyse big data as a } \\
\text { technology and as an } \\
\text { industrial activity, and to } \\
\text { identify the points of } \\
\text { weaknesses and ethical } \\
\text { concerns created by the } \\
\text { current business practices. }\end{array}$ & $\begin{array}{l}\text { Potential solutions are proposed } \\
\text { to address the stated concerns, to } \\
\text { build and maintain business } \\
\text { practices, and to respect ethical } \\
\text { standards as a prerequisite for a } \\
\text { sustainable big data industry. }\end{array}$ \\
\hline
\end{tabular}

While above studies have pointed to ethical issues concerning big data usage and management, prior studies have suggested ways to handle ethical concerns. Nair (2014) emphasised on having in place a framework of a code of ethics created in a sustainable ethics-oriented environment with the involvement and commitment of all the stakeholders, Nair and Saiz-Alvarez (2019) highlight the need of ethical governance for sustainable development. Referring to ethical issues that rise from reselling consumers' data to the secondary market for big data, Martin (2015) suggested implementing solutions that create value for all stakeholders, and alongside to preserve sustainable industry practices. Could these perspectives be incorporated into big data and be used to create value through stakeholders involvement, will be the focus of discussion in the following section.

\section{Addressing the issue of 'ethics in big data' through involving stakeholders}

Given the practical significance of big data across scientific, social and business contexts, researchers have been voicing their concerns. For instance, commenting that majority of the big data would be geo located across the world by 2020, Digitalised Development (2016) questions whether and how the existing legal owners of data (cyber corporations) would be willing to share this new source of competitive advantage, as this involves both 
threats and opportunities for the stakeholders. However, many others have also suggested ways to address 'ethics' in big data analytics and its management. Wielki (2015), referring to the social and ethical challenges in big data utilisation opined organisations should adopt internal practices like establishing ethical decision points that ensure synchronisation between the values established and practiced in data management and transparency also when dealing with customers and clients which build up trust, eliminating suspicions on big data initiatives. Floridi and Taddeo (2016) suggested developing a macro (data) ethics that address the diverse set of ethical implications of data science within a consistent, holistic and inclusive framework.

In fact, many prior studies feel involvement of stakeholders would be helpful in this regard. Uria-Recio (2018) feels given the scale and ease with which big data analytics are conducted today implies that the existing ethical-legal frameworks is likely to change completely and suggested including all stakeholders (data scientists, data engineers, database administrators, etc.) involved in handling big data on discussions regarding ethical usage of big data, giving due consideration to the five principles of big data ethics:

1 maintain privacy regarding customer identity and data

2 ensure confidentiality while sharing private information

3 maintain transparency; increase customers awareness on data usage

4 ensure non-interference of big data analytics with human minds will

5 no usage of big data to institutionalise unconscious/unfair biases like racism or sexism.

Of course, the effect of big data on the stakeholders may vary depending upon the industry, purpose, role, involvement of the stakeholder's, and so on. Incidentally, Center for Internet and Society and LIRNEasia (Hickok et al., 2017) conducted a mapping exercise to identify stakeholders who could be involved in the big data for development (public) specifically in the Global South countries. Finding inconsistencies with regards data sharing policies of research data published in the science, technology and medicine journals, Sturges et al. (2015) argues that although sharing of data ensures transparency, how the data is reused is very important and proposed developing a stakeholder driven model for journal data sharing policies to facilitate easy data sharing. Whereas, Günther et al. (2017) argues that for practical purposes organisations would continuously be required to realign work practices, organisational models, and stakeholder interests to reap benefits from big data. In the patient-centric healthcare system, while analysing the influence of big data on various stakeholders (patients, medical practitioners, hospital management, etc.) Palanisamy and Thirunavukarasu (2017) discussed how various healthcare frameworks developed using big data analytics could help in reaping quality knowledge, and disseminating the same to diversified healthcare stakeholders.

Interestingly, findings regarding ethicality on big data usage were even obtained from studies, conducted in different countries. For example, a study conducted by European Economic and Social Committee (2017) explored the ethical dimensions of big data (privacy, confidentiality, transparency, identity and free choice) in an attempt to balance them with the need for economic growth within the European Union. This study felt there was a need to empower people, make them understand the dynamics, interests and values that get affected by data analytics, given that they are not aware of how data could be 
used to predict their behaviour and shape their virtual identity. While, stakeholders' perceived benefits in a data driven economy as: smart solutions, customised/personalised service offerings, predicting customer preferences and behaviour, speeding up of scientific research, taking informed business decisions, improving quality of healthcare, and so on. Whereas, the risks and ethical issues in big data usage were perceived as data quality and breach issues, higher costs, no control over personal data usage, objectification, discrimination, and so on. Nonetheless, this study also suggested certain balancing actions to address the big data ethical issues through an EU privacy management portal/platform, ethical data management protocol (ED-Map), data management statement, European e-health database, digital education program on big data and a new European regulation on data protection.

Another example concerns open government data (OGD) usages which attract many stakeholders. Given that OGD initiatives call for the involvement of many persons, stakeholder analysis would help to gauge an understanding on the roles played by the different stakeholders, to map their power to impact the development and implementation of OGD, and also to determine their level of interest in the OGD (Gonzalez-Zapata and Heeks, 2015). By using stakeholder analysis to Chile's OGD initiative the study categorised stakeholder groups on the basis of their relative power and interests as:

a primary stakeholders (politicians, public officials, public sector practitioners, international organisations)

b secondary stakeholders (civil society activists, funding donors, ICT providers, academics)

c another stakeholder group, which, at times is associated with OGD although absent from significant involvement in Chile (private-sector and citizen-users).

This stakeholder analysis exercise helped to understand the key actors-stakeholders, different meanings-in the context of their OGD-relevant capacities, the incentives etc. they bring to OGD, prominence of different perspectives and the implications thereof, which is valuable when laying the foundation for those seeking to engage with any national OGD, added the researchers. Meanwhile, Granickas (2015) argued that with the constantly growing mutual expectations between governments, organisations and other stakeholders on ethical OGD re-use, it is important to take positive steps to create and implement policies that lead to increased trust and reputation, which would eventually lead to smoother processes for open data release, acquisition and re-use.

While the studies above reiterate the need for stakeholders involvement, Chessell (2014) argues that given all involved (the organisation, customers and stakeholders) may have different opinions on what is 'ethical', organisations need to be thoughtful when using the technology, and suggested using an ethical awareness framework that helps in developing ethical policies on usage of analytics and big data. While, Freitas et al. (2019) and Nair and Saiz-Alvarez (2019) stressed on the need of ethical governance for sustainable development, Martin (2015) felt firms in the big data industry need to address the ethical issues and problems through creating sustainable industrial practices. Incidentally, Steurer et al. (2005) describe the sustainable development-stakeholder relationship management (SD-SRM) perspective as a distinguishing research approach, which could be related to the wider body of stakeholder theory to achieve sustainable development. Additionally, Friedman and Miles's (2006) normative stakeholder theory 
concept states stakeholders should act and view the purpose of organisation on the basis of ethical principles.

Figure 1 Stakeholder analysis approach framework

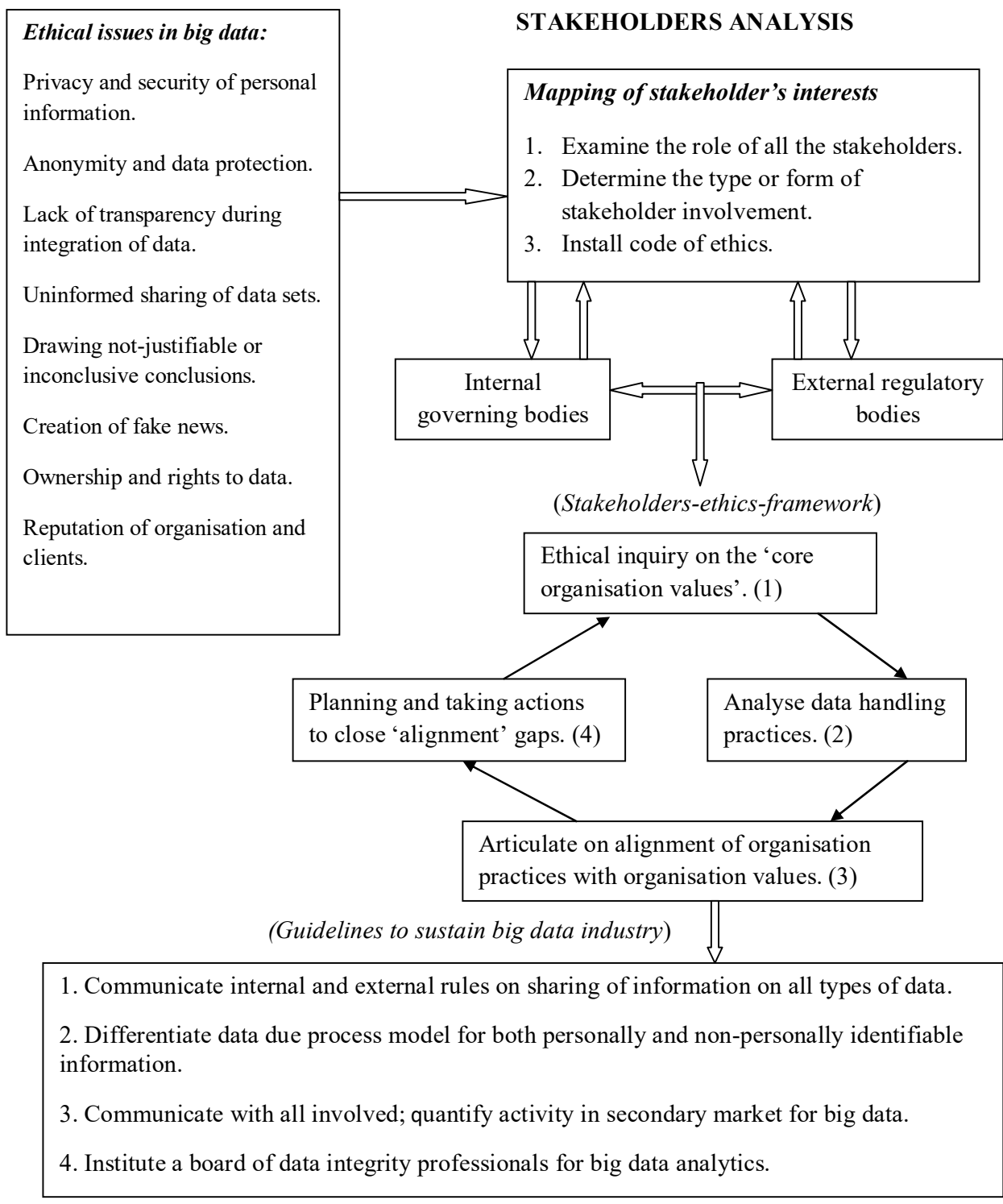

Source: Adapted from Davis and Patterson (2012) and Martin (2015)

Given that many studies have argued how stakeholders' involvement in big data management would be helpful, in the context of seeking answer to the research question, this study proposes to illustrate the importance and need of developing a stakeholderdriven model/framework (adapted from Davis and Potterson, 2012), suggested to be built with mutual interests through involvements that increase trust and reputation which 
should lead to a smoother process in data sharing and usage. Moreover, ethical governance is required for sustainable development observe Nair and Saiz-Alvarez (2019). Hence, mapping of stakeholders' interests linked to regulatory/governing bodies, to the stakeholders ethics framework to sustainability guidelines (Martin, 2015), keeping a sustainable perspective, is also indicated in the framework.

The proposed stakeholder-driven framework is illustrated in Figure 1.

As per the suggested 'stakeholder analysis approach framework' illustrated in Figure 1, duly taking into consideration the ethical issues in big data, a stakeholders analysis is to be conducted which begins with mapping of stakeholder's interests. This mapping process calls for:

a examining the role of all involved stakeholders (data providers, researchers, social scientists, fund providers, policy makers, government, industry, etc.)

b determining the functional activity for which the stakeholder is to be involved (researching, analysing, synthesising, reporting, influencing, using and supporting, developmental activities, etc.)

c installing a code of ethics (in consultation with the organisation and all the stakeholders).

Mapping of stakeholders interests should be conducted in consultation with the internal governing and external regulatory bodies so that there is a two-way interaction and communication which is explicit and transparent (especially containing the ethical components) between all involved.

Moreover, given the implications of the ethical issues on big data usage that affect individual persons in many ways (raises personal, privacy concerns regarding who own personal data, whether availability or presence of more data would influence ones reputation, and so on) could have an effect on the company brand name, customer relationship and profit in the long run. In view of this, it is vital that the ethical values and behavioural actions in big data usage and management be evaluated. For this purpose the current study proposed to include the four core components of the alignment methodology framework adapted from Davis and Patterson (2012, p.46) into its 'stakeholder-ethics framework' wherein, the interlinking of four core steps would involve:

1 ethical inquiry on the core organisation values

2 analysis of data handling practices

3 articulate alignment of organisation practices with organisation values

4 planning and taking actions to close 'alignment' gaps.

In fact, the main emphasis of the proposed framework should be on these four core steps, wherein this first core step requires an ethical inquiry to understand the core organisation values that drive the subsequent organisation's actions. The second step would determine how well actual data-handling practices are aligned to the core organisation values, the third step would help to articulate whether the organisation's practices are in alignment to its stated values (principles) and the last/fourth step calls for planning to work towards aligning values with actions to enable the organisation create a common and shared sense of purpose and action around the given business initiative. Moreover, rapidly evolving 
big data developments with enhanced capacities to generate huge volume of data can be used to create value for stakeholders, and build competitive advantage through adopting guidelines for sustainable big data practices opined, Martin (2015). Accordingly, the ethical issues that need to be addressed by incorporating the stakeholder-ethics framework process to leverage sustainable big data practices, is illustrated in the framework.

\section{Summary and conclusions}

Big data facilitates gathering of real-time data from millions of end users with the help of big data analytics enabling organisations to direct automate and optimise the decision making process, create knowledge and business models, influence organisational strategic making and gain competitive advantage. While, many studies elicit that evolving technological advancements and developments will continue to provide more stream of digitalised data requiring the integration of individuals, processes and organisations to use this information for the purpose of knowledge management, innovations, competitive advantage, add business value, and so on (Akter and Wamba, 2016; Elgendy and Elragal, 2016; Mazzei and Noble, 2017; Sivarajah et al., 2017), there are others who raised the question of ethics in big data analytics usage and applications (Chessell, 2014; Herschel and Miori, 2017; Hyrynsalmi et al., 2017; Martin, 2015). Nevertheless, given that organisations realise value from the stream of digitalised big data at different levels of integrated analysis involving individuals, processes and organisations (Günther et al., 2017; Knoppers and Thorogood, 2017), led to framing the research question: how to address the ethical concerns on data analytics usage from a sustainable perspective?

To answer this research question in this general review paper, prior studies referred suggested to consider stakeholders' perceptions on the issue of data sharing for development purposes (Sturges et al., 2015; Vayena et al., 2016), to involve stakeholders viewing the purpose of organisation on the basis of ethical principles (Friedman and Miles, 2006) and to ensure fair treatment of stakeholders and the integrity of big data (Institute of Big Ethics, 2016). Going by this, the current study sought to examine how ethical concerns in big data could be addressed through stakeholders' involvement and developed a 'stakeholders analysis approach framework' for this purpose.

The framework begins with 'mapping of stakeholders' interests', an important exercise given that it provides information on their roles, interests, initiatives towards big data developments and involvement in big data ethics discussions. This aspect is discussed in prior studies (Günther et al., 2017; Uria-Recio, 2018). In fact, a mapping exercise to identify the stakeholders for big data development purpose was conducted by the Center for Internet and Society and LIRNEasia (Hickok et al., 2017). Additionally, installing a 'code of ethics' in the mapping exercise could guide the stakeholders involved in big data development as it grows and evolves, simultaneously helping organisations shape their own internal guidelines on data usage and management. The importance of code of ethics has been highlighted in prior studies (Nair, 2014; Zwitter, 2014; Metcalf et al., 2016). Incidentally, the necessity of such platforms to balance actions when addressing the big data ethical issues was suggested by European Economic and Social Committee (2017). Figure 1 (framework) has also indicated the importance of functional ethics engagements through the interlinking of internal and external 
governance and regulatory bodies. This is in line to Metcalf and Crawford's (2016) argument on the need to have internal and external regulatory bodies so that big data practices are brought into frameworks of trust and accountability.

The main focus in the proposed framework is to be on the steps involved in stakeholder-ethics framework, which begins with ethical inquiry on the core organisation values, to analysing the data handling practices, to alignment of organisation practices with organisation values, and finally to plan and take corrective actions to close-up the 'alignment' gaps. This stakeholders-ethics-framework was adapted from the alignment methodology framework by Davis and Patterson (2012) who, contended that the approach can be used to engage in explicit ethical inquiry on big data usage in all types of situations. Although, this framework is useful, given that ethical effects of big data usages on stakeholders could vary based on the industry, stakeholders' involvements, their roles, etc. if need be, suitable modifications may have to be adopted. For, as Shams and Solima (2019) suggest insights can be developed on how to design, deliver and evaluate stakeholder value based on the verified data. Furthermore while stakeholders-ethics-framework would help towards gaining competitive advantage, organisations should strive for sustainable development, stated prior researchers (Freitas et al., 2019; Lokshina and Lanting, 2018; Steurer et al., 2005). In view of this, stakeholders-ethics-framework is shown to be interlinked to sustainability guidelines (Martin, 2015). Moreover, the proposed stakeholder analysis approach framework should help and guide organisations in big data analytics ethical usage through focusing on the information quality criteria of completeness and accuracy, is felt. In fact, this aspect is also in line to a previous study (Wanner and Janiesch, 2019) that had explored how to increase sustainability in reports using the potential of big data analytics.

\subsection{Limitations, implications and future research}

There are certain limitations to the study which are discussed hereunder. In the current age of digital technology while big data analytics are used across all fields of research, this 'general review' paper has reviewed selective studies on big data; to enable gain a general overview on the 'ethical concerns in big data management'. Hence, researchers interested in a specific area may be required to modify the stakeholder analysis approach framework accordingly. For example, in the field of marketing while there is an increase in consumers' who have adopted connected lifestyles, they are unaware of how information on their buying behaviour is collected, shared and applied. Although, for the marketer this information is increasingly complex, the onus of abiding by the ethical use of data (EUoD) falls on them. Hence, these marketers may have to use the framework focusing on the 'operationalisation' of data use ethics.

This study is based on information gathered through reviewing literature on prior studies regarding ethics in data analytics. However, given that big data analytics is a fast evolving phenomenon having far reaching consequences; it may help if an empirical/case study is applied to the proposed framework to understand its practical relevance.

Another limitation is related to the practical challenges in the usage of 'stakeholders analysis approach framework' to gain insights at various levels of decision making and realise value from ethical assessments of big data practices. Collecting and analysing big data at various levels would require a flexible organisation model that facilitate realising actual value in real-time; integrating external and internal big data resources with diverse 
stakeholders' interests into the organisation model, in line to the organisation core values. However, prior studies (Günther et al., 2017) found that at times the stakeholder concerns emerged only post/after the organisation has incorporated huge amounts of data into their business model. Thus, development of big data insights in line to the organisation core values along with stakeholders' interests may have practical challenges. Nevertheless, this implies addressing this limitation through future research which could inquire how to incorporate flexibility into the organisation development model so that emerging stakeholder's interests are accommodated and ethically addressed.

The study suggests using of the stakeholder analysis approach framework with the focus on sustainability of big data. This implies managers need to focus on sustainability and work towards effective, ethical big data management practices giving due consideration to diverse stakeholder's interests and involvements. A further implication is to apply the proposed framework by mapping stakeholders' interests, roles, form of involvement, installing the code of ethics and integrating external analytics into the existing organisation core values model (illustrated in Figure 1). Although prior studies (Martin, 2015; Uria-Recio, 2018; Verma, 2017; Wielki, 2015) have stated of practical challenges, organisations could individually make efforts to align their fundamental values with all data analytics sources to create effective interactions between all stakeholders, for their organisation's development.

In conclusion, it may be stated that in this age of digital technology revolution that facilitates access to big data portability and interconnectivity, for organisations to realise value ethically from big data would require continuous interactions and alignment between the organisation core values model, persons involved in big data analytics and the stakeholders' interests. Furthermore, as Martin (2015) stated given that the major benefits of big data include combining information from multiple sources for knowledge creation, better decision making, etc. there is a need to address the issue of ethics in big data on a continuous basis and work towards fostering a sustainable big data industry.

\section{References}

Abouelmehdi, K., Beni-Hssane, A., Khaloufi, H. and Saadi, M. (2017) 'Big-data security and privacy in healthcare: a review', The 8th International Conference on Emerging Ubiquitous Systems and Pervasive Networks (EUSPN 2017)/The 7th International Conference on Current and Future Trends of Information and Communication Technologies in Healthcare (ICTH-2017)/Affiliated Workshops, in Shakshuki, E. (Ed.): Procedia Computer Science, Vol. 113, pp.73-80.

Ahmad, K., JianMing, Z. and Rafi, M. (2019) 'An analysis of academic librarians competencies and skills for implementation of big data analytics in libraries: a correlational study', Data Technologies and Applications, Vol. 53, No. 2, pp.201-216.

Akter, S. and Wamba, S.F. (2016) 'Big data analytics in e-commerce: a systematic review and agenda for future research', Electron Markets, Vol. 26, No. 2, pp.173-194.

Anshari, M. and Alas, Y. (2015) 'Smartphones habits, necessities, and big data challenges', Journal of High Technology Management Research, Vol. 26, No. 2, pp.177-185.

Blackburn, M., Alexander, J., Legan, J.D. and Klabjan, D. (2017) 'Big data and the future of R\&D management', Research-Technology Management, Vol. 60, No. 5, pp.43-51.

Bumblauskas, D., Nold, H., Bumblauskas, P. and Igou, A. (2017) 'Big data analytics: transforming data to action', Business Process Management Journal, Vol. 23, No. 3, pp.703-720. 
Chessell, M. (2014) Ethics for Big Data and Analytics, IBM [online] https://www.ibmbigdatahub.com/sites/default/files/whitepapers_reports_file/TCG\%20Study\% 20Report\%20-\%20Ethics\%20for\%20BD\&A.pdf (accessed 12 June 2018).

Davis, K. and Patterson, D. (2012) Ethics of Big Data: Balancing Risk and Innovation, O'Reilly Media, Sebastopol.

De Mauro, A., Greco, M. and Grimaldi, M. (2015) 'What is big data? A consensual definition and a review of key research topics', in AIP Conference Proceedings, AIP Publishing, February, Vol. 1644, No. 1, pp.97-104.

Del Vecchio, P., Secundo, G. and Passiante, G. (2018) 'Analyzing big data through the lens of customer knowledge management: evidence from a set of regional tourism experiences', Kybernetes, Vol. 47, No. 7, pp.1348-1362.

Devlin, B. (2017) The New Ethics of Data Management, Upside, 10 July [online] https://tdwi.org/ articles/2017/07/10/biz-all-new-ethics-of-data-management.aspx (accessed 12 December 2018).

Digitalised Development (2016) Big Data - A Stakeholder Analysis [online] https://wpmu.mah.se/ nmict161 group4/2016/03/10/big-data-a-stakeholder-analysis/ (accessed 15 February 2019).

Elgendy, N. and Elragal, A. (2016) 'Big data analytics in support of the decision making process', Procedia Computer Science, Vol. 100, pp.1071-1084.

Emani, C.K., Cullot, N. and Nicolle, C. (2015) 'Understandable big data: a survey', Computer Science Review, Vol. 17, No. C, pp.70-81 [online] https://www.cs.helsinki.fi/u/jilu/ paper/bigdatasurvey01.pdf (accessed 12 August 2018).

European Economic and Social Committee (2017) The Ethics of Big Data: Balancing Economic Benefits and Ethical Questions of Big Data in the EU Policy Context [online] https://www.eesc.europa.eu/resources/docs/qe-02-17-159-en-n.pdf (accessed 15 February 2019).

Floridi, L. and Taddeo, M. (2016) What is Data Ethics?, p.374, Philosophical Transactions-The Royal Society A [online] https://royalsocietypublishing.org/doi/pdf/10.1098/rsta.2016.0360 (accessed 19 February 2019).

Fredriksson, C. (2018) 'Big data creating new knowledge as support in decision-making: practical examples of big data use and consequences of using big data as decision support', Journal of Decision Systems, Vol. 27, No. 1, pp.1-18.

Freitas, A.C., Quaresma, P., Balbino, A.d.C., Costa, R P., Ruivo, I.S., Rato, L. and Calado, J.G. (2019) 'Ethical governance for sustainable development in higher education institutions: lessons from a small-scale university', in Nair, S.R. and Saiz-Alvarez, J.M. (Eds.): Handbook of Research on Ethics, Entrepreneurship, and Governance in Higher Education, IGI Global, Hershey, USA, pp.214-237.

Friedman, A.L. and Miles, S. (2006) Stakeholders: Theory and Practice, Oxford University Press, UK.

Gandomi, A. and Haider, M. (2015) 'Beyond the hype: Big data concepts, methods, and analytics', International Journal of Information Management, Vol. 35, No. 2, pp.137-144.

Gonzalez-Zapata, F. and Heeks, R. (2015) 'The multiple meanings of open government data: understanding different stakeholders and their perspectives', Government Information Quarterly, Vol. 32, No. 4, pp.441-452.

Granickas, K. (2015) Ethical and Responsible Re-use of Open Government Data, European Public Sector Information Platform Topic Report No. 2015/02 [online]. https:/www.europeandataportal.eu/sites/default/files/2015_ethical_and_responsible_use_of_o pen_government_data.pdf (accessed 24 February 2019).

Günther, W.A., Mehrizi, M.H R., Huysman, M. and Feldberg, F. (2017) 'Debating big data: a literature review on realizing value from big data', The Journal of Strategic Information Systems, Vol. 26, No. 3, pp.191-209. 
Harrison, R., Parker, A., Brosas, G., Chiong, R. and Tian, X. (2015) 'The role of technology in the management and exploitation of internal business intelligence', Journal of Systems and Information Technology, Vol. 17, No. 3, pp.247-262.

Herschel, R. and Miori, V.M. (2017) 'Ethics \& big data', Technology in Society, Vol. 49, pp.31-36 [online]

http://www.informatica.uniroma2.it/upload/2017/IA2/HerschellMioriEthicsAndBigData.pdf (accessed 12 June 2018).

Hickok, E., Sinha, A., Rakesh, V., Lokanathan, S. and Perera-Gomez, T. (2017) Systematic Mapping of Big Data for Development Stakeholders with A Focus on the 'Global South: Final Report', IDRC Digital Library [online] https://idl-bnc-idrc.dspacedirect.org/bitstream/handle/ 10625/56908/IDL-56908.pdf? sequence=2 (accessed 15 February 2019).

Hyrynsalmi S., Kimppa K.K., Koskinen, J., Smed, J. and Hyrynsalmi S. (2017) 'The shades of grey: datenherrschaft in data-driven gamifcation', in Meder, M., Rapp, A., Plumbaum, T. and Hopfgartner, F. (Eds.): Proceedings of the Data-Driven Gamification Design Workshop, Tampere, Finland, 20 September [online] http://ceur-ws.org/Vol-1978/paper1.pdf (accessed 12 June 2018).

Institute of Big Ethics (2016) Business Ethics and Big Data, Business Ethics Briefing, No. 52 [online] https://www.ibe.org.uk/userassets/briefings/b52_bigdata.pdf (accessed 15 February 2019).

Knoppers, B.M. and Thorogood, A.M. (2017) 'Ethics and big data in health', Current Opinion in Systems Biology, Vol. 4, pp.53-57, in Falter-Braun, P. et al. (Eds.): Big Data Acquisition and Analysis Pharmacology and Drug Discovery [online] https://www.sciencedirect.com/science/ article/pii/S2452310017300264 (accessed 12 June 2018).

LaBrie, R.C., Cazier, J.A. and Steinke, G.H. (2014) 'Big data ethics: a longitudinal study of consumer, business and societal perceptions', Journal of Management Systems, Vol. 24, No. 2, pp.23-38.

Lee, I. (2017) 'Big data: dimensions, evolution, impacts, and challenges', Business Horizons, Vol. 60, No. 3, pp.293-303.

Lipska, K. and Kijanka, E. (2019) 'To take or not to take? The importance of business ethics', in Nair, S.R. and Saiz-Alvarez, J.M. (Eds.): Handbook of Research on Ethics, Entrepreneurship, and Governance in Higher Education, IGI Global, Hershey, pp.137-155.

Lokshina, I.V. and Lanting, C.J. (2018) 'Addressing ethical concerns of big data as a prerequisite for a sustainable big data industry', International Journal of Interdisciplinary Telecommunications and Networking, Vol. 10, No. 3, pp.33-54.

Martin, K.E. (2015) 'Ethical issues in the big data industry', MIS Quarterly Executive, Vol. 14, No. 2, pp.67-85.

Mazzei, M.J. and Noble, D. (2017) 'Big data dreams: a framework for corporate strategy', Business Horizons, Vol. 60, No. 3, pp.405-414.

Metcalf, J. and Crawford, K. (2016) 'Where are human subjects in big data research? The emerging ethics divide', Big Data \& Society, Vol. 3, No. 1, pp.1-14.

Metcalf, J., Keller, E.F. and Boyd. D. (2016) Perspectives on Big Data, Ethics, and Society, Council for Big Data, Ethics, and Society, 23 May [online] https://bdes.datasociety.net/ council-output/perspectives-on-big-data-ethics-and-society/ (accessed 11 June 2019).

Mittelstadt, B.D. and Floridi, L. (2016) 'The ethics of big data: current and foreseeable issues in biomedical contexts', Science and Engineering Ethics, Vol. 22, No. 2, pp.303-341.

Mukred, M.A.A. and Jianguo, Z. (2017) 'Use of big data to improve environmental sustainability in developing countries', International Journal of Business and Management, Vol. 12, No. 11, pp.249-256.

Nair, S.R. (2014) 'Ethics in higher education', in Baporikar, N. (Ed.): Handbook of Research on Higher Education in the MENA Region: Policy and Practice, IGI Global, Hershey, USA, pp.230-260. 
Nair, S.R. and Saiz-Alvarez, J.M. (2019) Handbook of Research on Ethics, Entrepreneurship, and Governance in Higher Education, IGI Global, Hershey, USA.

Oussous, A., Benjelloun, F-Z., Lahcen, A.A. and Belfkih, S. (2018) 'Big data technologies: a survey', Journal of King Saud University-Computer and Information Sciences, Vol. 30, No. 4, pp.431-438.

Palanisamy, V. and Thirunavukarasu, R. (2017) 'Implications of big data analytics in developing healthcare frameworks - a review', Journal of King Saud University-Computer and Information Sciences [online] https://www.sciencedirect.com/science/article/pii/ S1319157817302938 (accessed 4 February 2019).

Pauleen, D.J and Wang, W.Y.C. (2017) 'Does big data mean big knowledge? KM perspectives on big data and analytics', Journal of Knowledge Management, Vol. 21, No. 1, pp.1-6.

Shams, S.M.R. and Solima, L. (2019) 'Big data management: implications of dynamic capabilities and data incubator', Management Decision, in press [online] https://doi.org/10.1108/MD-072018-0846.

Sharma, R., Mithas, S. and Kankanhalli, A. (2014) 'Transforming decision-making processes: a research agenda for understanding the impact of business analytics on organizations', European Journal of Information Systems, Vol. 23, No. 4, pp.433-441.

Sivarajah, U., Kamal, M.M., Irani, Z. and Weerakkody, V. (2017) 'Critical analysis of big data challenges and analytical methods', Journal of Business Research, Vol. 70, pp.263-286 [online] https://www.sciencedirect.com/science/article/pii/S014829631630488X (accessed 12 August 2018).

Srinivasa, K.G., Sowmya, B.J., Shikhar, A., Utkarsha, R. and Singh, A. (2018) 'Data analytics assisted internet of things towards building intelligent healthcare monitoring systems: IoT for healthcare', Journal of Organizational and End User Computing, Vol. 30, No. 4, pp.83-103.

Steurer, R., Langer, M.E. and Konrad, A. (2005) 'Corporations, stakeholders and sustainable development I: a theoretical exploration of business-society relations', Journal of Business Ethics, Vol. 61, No. 3, pp.263-281.

Sturges, P., Bamkin, M., Anders, J.H.S., Hubbard, B., Hussain, A. and Heeley, M. (2015) 'Research data sharing: developing a stakeholder-driven model for journal policies', Journal of the Association for Information Science and Technology, Vol. 66, No. 12, pp.2445-2455.

Uria-Recio, P. (2018) 5 Principles for Big Data Ethics, Towards Data Science, 14 September [online] https://towardsdatascience.com/5-principles-for-big-data-ethics-b5df1d105cd3 (accessed 18 February 2019).

Vayena, E., Gasser, U., Wood, A., O’Brien, D.R. and Altman, M. (2016) 'Elements of a new ethical framework for big data research', Washington and Lee Law Review Online, Vol. 72, No. 3 [online] https://projects.iq.harvard.edu/files/privacytools/files/elements_of_a_new_ ethical_framework_for_big_data_research_1.pdf (accessed 26 February 2019).

Verma, S. (2017) 'Big data and advance analytics: architecture, techniques, applications, and challenges', International Journal of Business Analytics, Vol. 4, No. 4, pp.21-47.

Vershinina, N., Rodgers, P., Tarba, S., Khan, Z. and Stokes, P. (2019) 'Gaining legitimacy through proactive stakeholder management: the experiences of high-tech women entrepreneurs in Russia', Journal of Business Research, in press [online] https://doi.org/10.1016/j.jbusres. 2018.12.063.

Wanner, J. and Janiesch, C. (2019) 'Big data analytics in sustainability reports: an analysis based on the perceived credibility of corporate published information', Business Research, Vol. 12, No. 1, pp.143-173.

Wielki, J. (2015) 'The social and ethical challenges connected with the big data phenomenon', Polish Journal of Management Studies, Vol. 11, No. 2, pp.192-202.

Zwitter, A. (2014) 'Big data ethics', Big Data \& Society, Vol. 1, No. 2, pp.1-6. 